\title{
Effects of trace Cr on as-cast microstructure and microstructural evolution of semi-solid isothermal heat treatment ZC61 magnesium alloy
}

\author{
* Xiao-feng Huang, Ya-jie Ma, Qiao-qiao Zhang, Lang-lang Wei, and Jian-qiao Yang \\ State Key Laboratory of Advanced Processing and Recycling of Nonferrous Metals, Lanzhou University of Technology, Lanzhou 730050, China
}

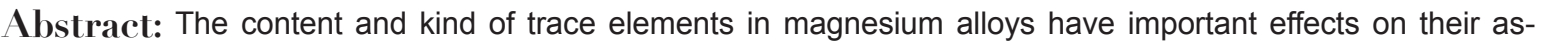

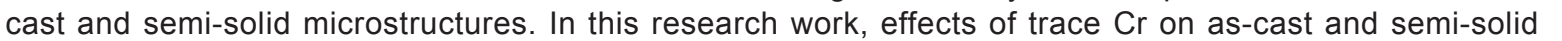

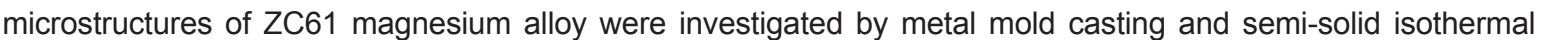
heat treatment. The results show that the addition of $\mathrm{Cr}$ can refine the $\alpha-\mathrm{Mg}$ phase without generating a new

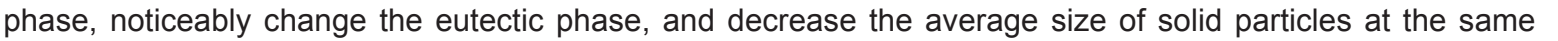

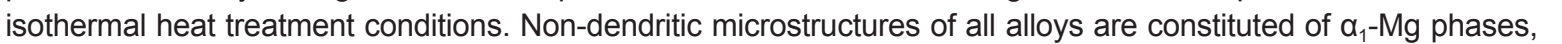

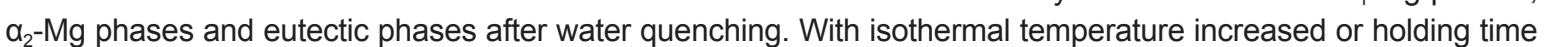
prolonged, the eutectic microstructure $(\alpha-M g+M g Z n+C u M g Z n)$ at the grain boundaries in as-cast alloy is melted

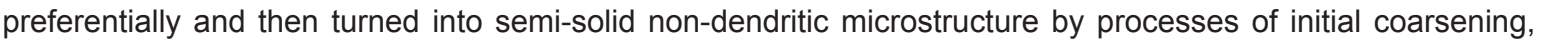
microstructure separation, spheroidizing and final coarsening. Especially when the ZC61-0.1Cr alloy was treated

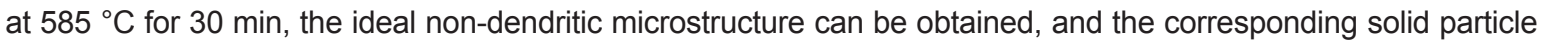
size and shape factor were $37.5 \mu \mathrm{m}$ and 1.33, respectively. The coarsening process of solid $\alpha-M g$ phase at higher

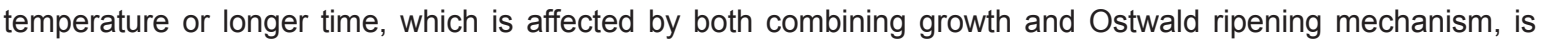

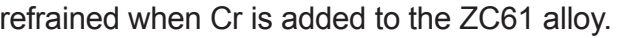

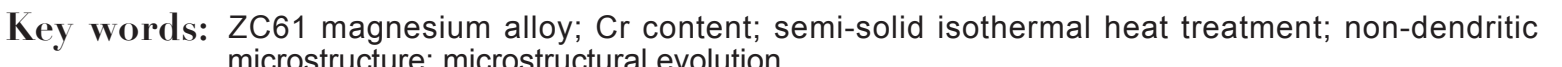
CLC numbers: TG146.22 Document code: A

Article ID: 1672-6421(2019)01-053-10

\begin{abstract}
A s light-weight metal structural materials, magnesium alloys exhibit a wide range of potential application, especially in automotive and aerospace industries, due to their excellent properties such as low density, high specific strength and stiffness, excellent castability and lightness in weight ${ }^{[1-2]}$. However, compared to aluminum alloys and steels, despite their benefit in reducing weight enormously, the mechanical properties of cast and wrought magnesium alloys are still inadequate for a wider application ${ }^{[3]}$. Improving the mechanical properties of magnesium alloys is one of the most important scientific issues for
\end{abstract}

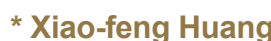

口

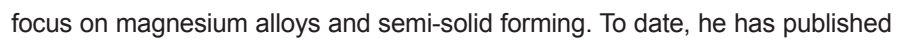

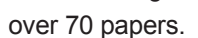

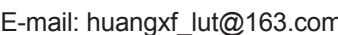

प researchers. It was reported that semi-solid metal (SSM) processing combined the advantages of casting and metal forming processes for near net shape production of engineering components, thus effectively improving mechanical properties ${ }^{[4-5]}$. SSM processing has a good applicability in the formation of magnesium alloys, and semi-solid forming components can be heat treated, thus their mechanical properties can be improved. In general, to product the semi-solid metal slurry or ingots is one of the most important steps in SSM processing. At present, the methods of obtaining a nondendritic microstructure mainly include mechanical stirring (MS), electromagnetic stirring (ES), straininduced melt activation (SIMA), spray deposition (SD), liquidus cast, and semi-solid isothermal heat treatment (SSIHT) ${ }^{[6]}$. Among these methods, SSIHT is a method developed in the middle of the 1990s, which is a process of secondary heating to obtain non-dendritic microstructure before semi-solid forming. The method has a potential development due to the simple 
technological process and low cost of preparation. Currently, SSIHT is only used in some commercial magnesium alloys, such as AZ91 magnesium alloys ${ }^{[7]}$.

Alloying or micro-alloying is a frequently-used method to effectively improve the microstructures and properties of magnesium alloys. Domestic and foreign scholars have done a lot of researches in the field ${ }^{[8]}$. In $\mathrm{Mg}$ - $\mathrm{Zn}$ based alloys, one of the commonly used magnesium alloy systems, the main alloying or micro-alloying elements are $\mathrm{Al}, \mathrm{Cu}, \mathrm{Zr}$, and $\mathrm{RE}$ ${ }^{[9]}$. In $\mathrm{Mg}-\mathrm{Zn}$-based alloys, $\mathrm{Mg}-\mathrm{Zn}-\mathrm{Cu}$ alloy is a new type of alloy, such as alloys of ZC61, ZC63 and ZC71 ${ }^{[10]}$. However, excessive $\mathrm{Cu}$ content is not conducive to improve corrosion resistance and mechanical properties of magnesium alloys, but the fourth micro-elements, such as $\mathrm{Zr}^{[11]}, \mathrm{Mn}^{[12]}$ and $\mathrm{RE}{ }^{[13]}$, can improve these properties. Moreover, Buha ${ }^{[14]}$ reported that $\mathrm{Cr}$ element can improve properties and refine grains of magnesium alloys. Therefore, in this work, $\mathrm{Cr}$ was added as the fourth micro-element to the $\mathrm{Mg}-\mathrm{Zn}-\mathrm{Cu}$ alloy to study the effects of $\mathrm{Cr}$ contents, holding times and temperatures on the microstructural evolution during semi-solid isothermal heat treatment. The goal is to obtain ideal semi-solid globular microstructures and provide experimental basis for semi-solid alloys design and alloying elements selection, even for semisolid forming in later stages.

\section{Experimental procedures}

The composition of experimental alloys is shown in Table 1. Alloys were prepared from high purity $\mathrm{Mg}, \mathrm{Zn}$ and $\mathrm{Cu}$ ingots (99.9wt.\%), and $\mathrm{Cr}$ particles (99.95wt.\%); all metals were melted at a pit-type electric resistance furnace named SG2-7.5 kW under protective RJ-2 covering flux and Ar atmosphere. When $\mathrm{Mg}$ ingots were totally melted, $\mathrm{Zn}$ and $\mathrm{Cu}$ ingots preheated to $200{ }^{\circ} \mathrm{C}$ were added to the magnesium liquid at $680{ }^{\circ} \mathrm{C}$. When the melting temperature rose to $760{ }^{\circ} \mathrm{C}$, $\mathrm{Cr}$ particles preheated to $200{ }^{\circ} \mathrm{C}$ were added to the melt and kept for $\sim 30 \mathrm{~min}$. Next, to refine and remove scum at $730^{\circ} \mathrm{C}$, $\mathrm{C}_{2} \mathrm{Cl}_{6}$ refining agent with a weight ratio of 1:500 compared with the melt was added to the melt by mechanical stirring for 2-3 min. Subsequently, at $710{ }^{\circ} \mathrm{C}$, after being held for $10-$ $15 \mathrm{~min}$, the melt was poured into a permanent mould made of steel preheated to $200{ }^{\circ} \mathrm{C}$. The specimens treated by SSIHT had the same size of $\Phi 15 \mathrm{~mm} \times 15 \mathrm{~mm}$.

To study the effects of $\mathrm{Cr}$ addition on as-cast microstructures and especially semi-solid microstructural evolution, the

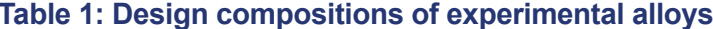

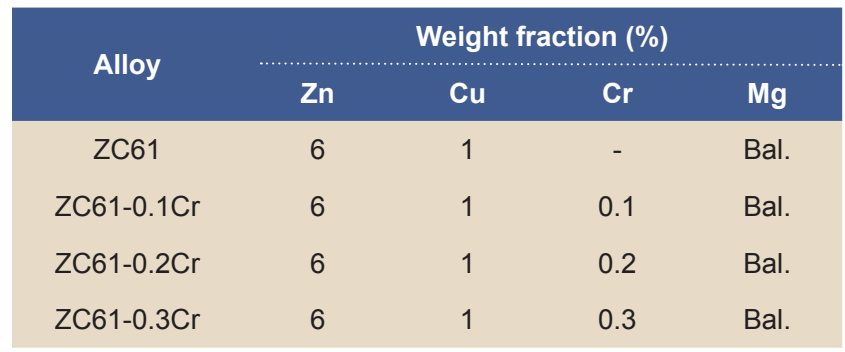

specimens were put into an iron crucible and covered with RJ-2 covering flux for protection. Next, the crucible was placed in a box-type resistance furnace for the SSIHT, i.e. isothermally heated at $575{ }^{\circ} \mathrm{C}$ and $595{ }^{\circ} \mathrm{C}$ for $30 \mathrm{~min}$, and at $585^{\circ} \mathrm{C}$ for $15,30,45$ and $60 \mathrm{~min}$. All specimens were quenched in cold water at room temperature. All as-cast and semi-solid specimens were mechanically polished and etched by $4 \% \mathrm{HNO}_{3}$ alcohol and $8 \% \mathrm{HNO}_{3}$ water solution to observe microstructure. The as-cast and semi-solid specimens were observed by MEF-3 metallographic microscope. The microstructures were studied by a JSM-6700F scanning electron microscope (SEM) equipped with energy dispersive spectroscopy (EDS) microanalyzer. X-ray diffraction (XRD) analysis of as-cast alloy specimens was detected using a D/ max-2400 type X-ray diffractometer operated at a $\mathrm{Cu} \mathrm{K \alpha}$ radiation, $40 \mathrm{kV}$ and $100 \mathrm{~mA}$ with a scanning rate of $5^{\circ} \cdot \mathrm{min}^{-}$ ${ }^{1}$ and the scanning range from $10^{\circ}$ to $90^{\circ}$. The statistics of the average particle size $\left(d_{0}\right)$, shape factor $\left(f_{0}\right)$ and solid fraction of ZC61- $x$ Cr alloys during semi-solid microstructural evolution were calculated using Image Pro-plus 6.0 software according to the following formulas ${ }^{[15]}$ :

$$
\begin{gathered}
d_{0}=\frac{\sum 2\left(\frac{A_{0}}{\pi}\right)^{\frac{1}{2}}}{n} \\
f_{0}=\frac{\frac{\sum p_{0}^{2}}{4 \pi A_{0}}}{n}
\end{gathered}
$$

where $A_{0}\left(\mu \mathrm{m}^{2}\right)$ is the area of each solid particle, $n$ is the total particles numbers and $P_{0}(\mu \mathrm{m})$ is the perimeter of each solid particle. If $f_{0}$ value closesto be 1 , the solid particles tend to be perfectly globular.

\section{Results and discussion}

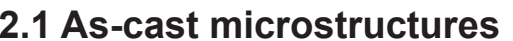

The OM images of as-cast ZC61- $x \mathrm{Cr}(x=0,0.1,0.2,0.3)$ magnesium alloys are shown in Fig. 1. It can be observed that these as-cast alloys show typical microstructures of nonequilibrium solidification with dendritic structure, which is constituted by $\alpha-\mathrm{Mg}$ matrix phases (white parts in Fig. 1), with continuous or semi-continuous reticular eutectic phases (black parts in Fig. 1) distributing along grain boundary and a few particles isolating or dispersing inside grains. As shown in the ellipse parts of Fig. 1, compared with microstructure without $\mathrm{Cr}$ element added (Fig. 1a), the microstructures adding $\mathrm{Cr}$ element show noticeable changes. When the content of $\mathrm{Cr}$ is $0.1 \mathrm{wt} . \%$ (Fig. 1b), the microstructure is composed of fine bulk grains, nearly equiaxed grains and rosette-like dendrites. It is found that the dendrite morphologies become developed and slightly coarsened after adding $0.2 \mathrm{wt} . \% \mathrm{Cr}$ (Fig. 1c). Especially when the content of $\mathrm{Cr}$ increases to $0.3 \mathrm{wt} . \%$ (Fig. 1d), a large number of non-equilibrium eutectic phases distribute along grains or dendrite boundaries and further coarsen. This probably because the solubility of $\mathrm{Cr}$ is limited 



in magnesium ${ }^{[16]}$ and enriched at grain boundaries.

The XRD results of ZC61- $x \mathrm{Cr}(x=0,0.1,0.2,0.3)$ alloys are shown in Fig. 2. It can be observed that there is no $\mathrm{Cr}$ phase formed after adding different contents of $\mathrm{Cr}$ and all alloys contain $\alpha-\mathrm{Mg}, \mathrm{CuMgZn}$ and $\mathrm{MgZn}_{2}$ phases, this result is similar to the Ref. [17]. Compared with the XRD pattern of the as-cast ZC61 alloy without adding Cr element, the intensity of $\mathrm{CuMgZn}$ diffraction peak is reduced after adding $\mathrm{Cr}$ element. This may be due to the strong interaction between $\mathrm{Cu}$ and $\mathrm{Cr}$ elements when $\mathrm{Cr}$ is added ${ }^{[18]}$, which affects the precipitation of the $\mathrm{CuMgZn}$ phase. $\mathrm{CuMgZn}$ phase, which is a C15-type Laves intermetallic compound phase with $\mathrm{MgCu}_{2}$ cubic structure ${ }^{[19]}$, can strengthen the matrix and grain boundary of the alloy when the content of $\mathrm{Cu}$ is lower in the $\mathrm{Mg}-\mathrm{Zn}-\mathrm{Cu}$ alloys ${ }^{[20]}$.

In this work, to further confirm compositions and demonstrate subtle characteristics, the alloys have undergone EDS microanalysis considering the similarity of the microstructures after adding $\mathrm{Cr}$ element. The SEM high-magnification micrographs are shown in Fig. 3 and the corresponding EDS results are shown in Table 2. It can be seen from Fig. 3 that the eutectic phases of these alloys show the thin sheet-like and fishbone characteristics, and the eutectic phases are mainly consisted of white and dark gray compounds. Especially when $\mathrm{Cr}$ is added, white eutectic compounds relatively reduce, and the amount of thin sheet-like microstructures increase. However, the $\mathrm{Cr}$ element is still not detected by EDS (Table 2) due to the low solubility of $\mathrm{Cr}$ in $\mathrm{Mg}$ according to binary $\mathrm{Mg}-\mathrm{Cr}$ phase

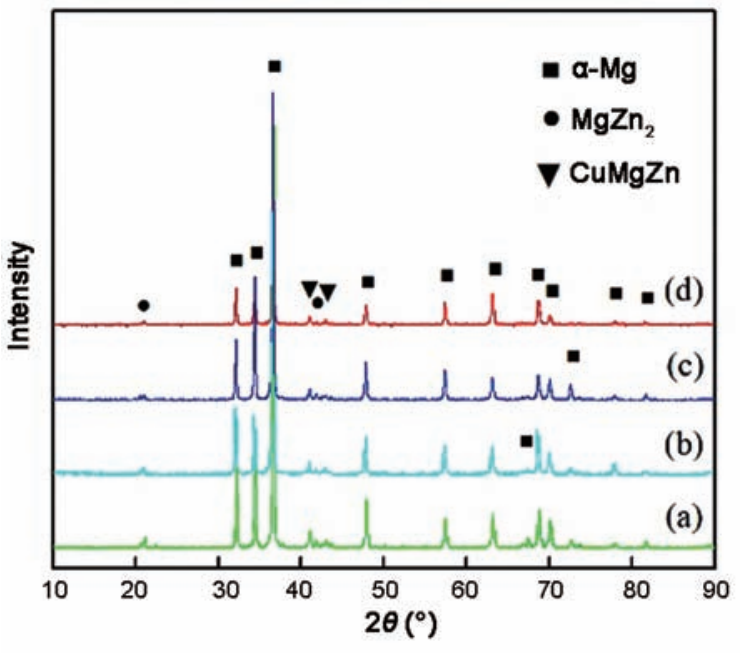

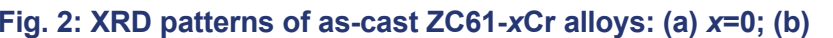

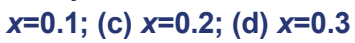

diagram ${ }^{[21]}$. But this does not mean the $\mathrm{Cr}$ element does not exist, because Buha ${ }^{[16]}$ certified that a trace element $\mathrm{Cr}$ with content of 0.05 at. $\%$ did dissolve in the magnesium lattice in the presence of $\mathrm{Zn}$ in the Mg-6Zn-0.2Cr alloy. For ZC61 and ZC61$0.1 \mathrm{Cr}$ alloys, white phases isolated in the matrix (marked $\mathrm{C}$ and $\mathrm{F}$ ) and lamellar dark gray phases (marked A, B and E) all contain $\mathrm{Mg}, \mathrm{Zn}$ and $\mathrm{Cu}$ atoms, so these compounds are consisted of $\alpha-\mathrm{Mg}+\mathrm{MgZn}_{2}+\mathrm{CuMgZn}$ combined with XRD results; and dark gray phases (marked D) circled by blue where the atomic 

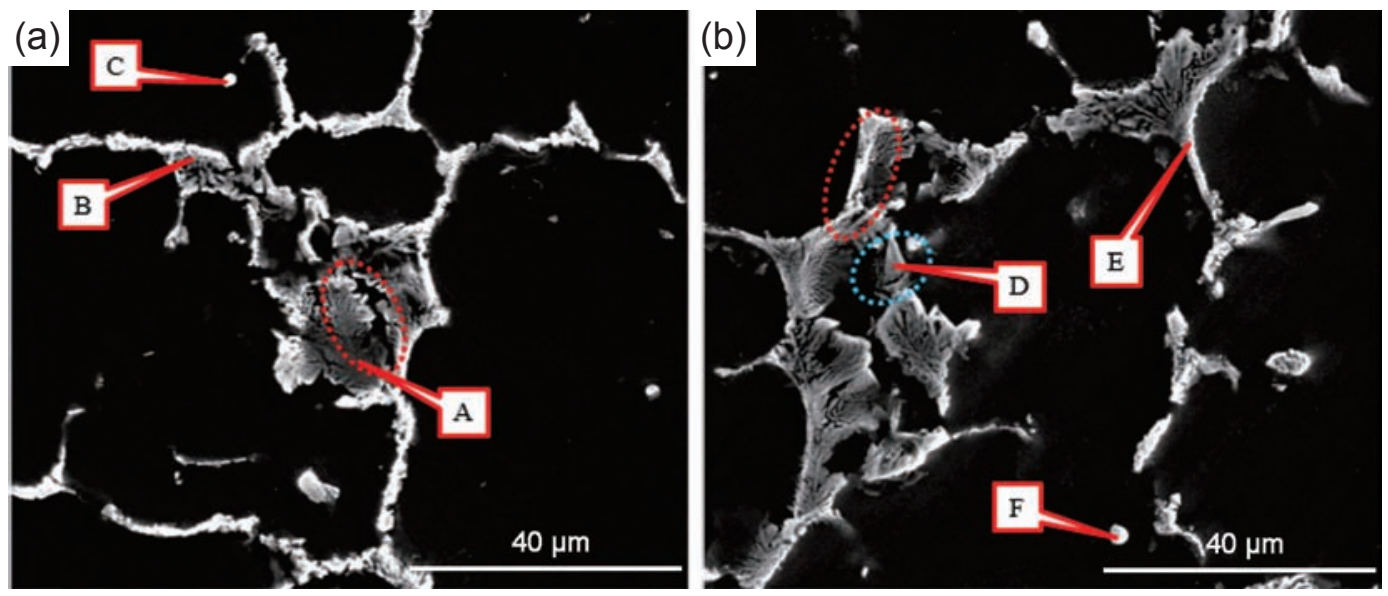

Fig. 3: SEM high-magnification micrographs of as-cast alloys: (a) ZC61; (b) ZC61-0.1Cr

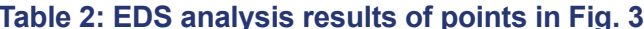

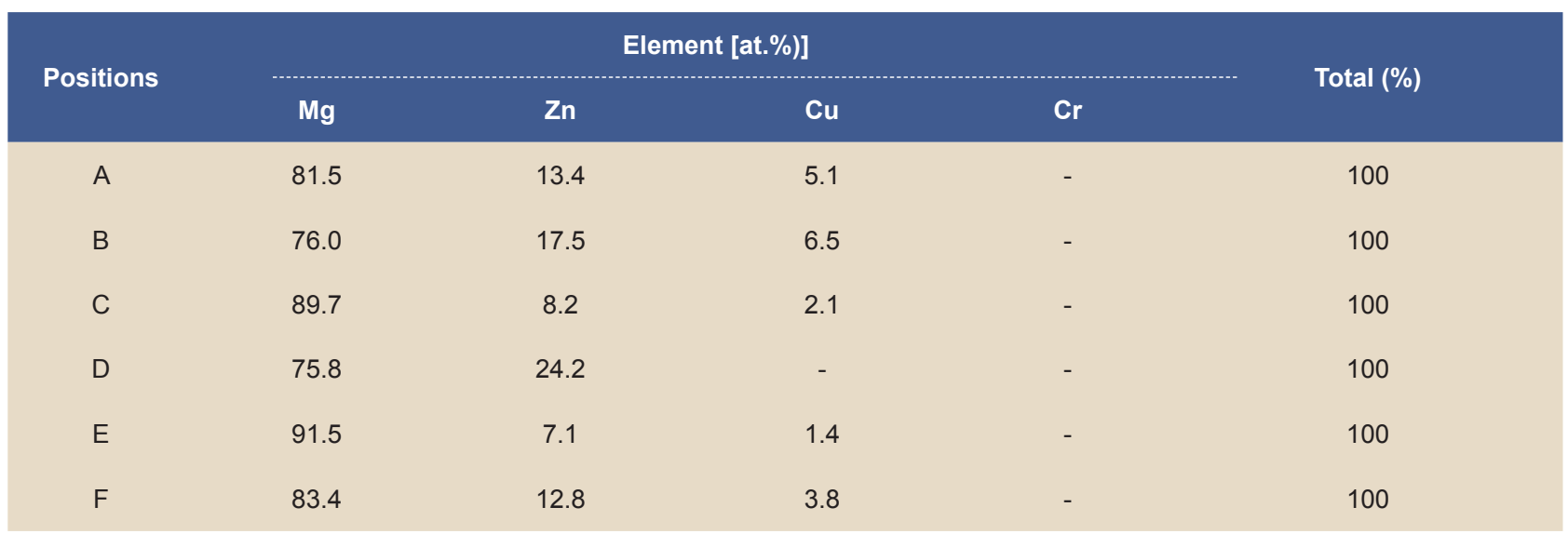

ratio of $\mathrm{Mg}$ to $\mathrm{Zn}$ without $\mathrm{Cu}$ approaching 3:1 is determined as $\alpha-\mathrm{Mg}+\mathrm{MgZn}_{2}$ mixed phases.

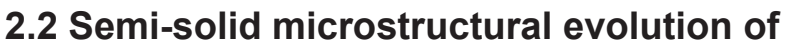

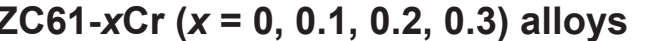

\subsubsection{Effects of different $\mathrm{Cr}$ contents and isothermal temperatures on non-dendritic microstructural evolution of ZC61 alloy}

Semi-solid non-dendritic microstructure of ZC61- $x \mathrm{Cr}(x=0$, $0.1,0.2,0.3)$ alloys at different temperatures for $30 \mathrm{~min}$ are shown in Fig. 4, and index statistics of solid fraction, shape factor and particle size of the correspond alloys are shown in Fig. 5.

As observed from the horizontal direction of Fig. 4, with the increase of holding temperature, original dendritic microstructures in all alloys are turned into a semi-solid nondendritic microstructure via initial coarsening, microstructure separation, spheroidizing and final coarsening. The sizes of solid particles and shape factors of experimental alloys with or without added $\mathrm{Cr}$ element, decrease first, and then increase, and solid fraction continuously decreases, corresponding to Fig. 5(a) to (c). Meanwhile, there are "liquid pools" with different sizes inside solid particles, and the larger "liquid pools" relatively increases (from $a_{1}$ to $a_{3}, b_{1}$ to $b_{3}, c_{1}$ to $c_{2}$ and $d_{1}$ to $\mathrm{d}_{3}$ ). A large number of "liquid pools" contain greater interface energy, which needs to be reduced to maintain equilibrium of solid and liquid phases, so "liquid pools" will grow and merge to form larger "liquid pools" ${ }^{[22]}$. When experimental alloys are isothermally heat-treated at $575{ }^{\circ} \mathrm{C}$ for $30 \mathrm{~min}$, some of eutectic microstructures are remelted and evolved into liquid phases, and the primitive dendrite microstructures have been divided into primary $\alpha-\mathrm{Mg}$ particles with irregular or nearly spherical shapes surrounded by a certain amount of liquid phases. In a few areas, some solid particles still adhere to each other and the spacing of particles is small because of low isothermal temperature. At $575^{\circ} \mathrm{C}$ holding for $30 \mathrm{~min}$, the average particle size, shape factor and solid fraction are 44-65 $\mu \mathrm{m}, 1.4-1.6$ and $68.5 \%-73 \%$, respectively.

When the temperature is increased to $585{ }^{\circ} \mathrm{C}$, the size and amount of irregular or bulk $\alpha-\mathrm{Mg}$ particles decrease, while concurrently, the amount of nearly spherical $\alpha$-Mg particles and the fraction of liquid increase. The spheroidization tendency of solid particles is more obvious, solid particles evenly distribute and become near to round. It is mainly 
attributed to high temperature to accelerate the dissolution of eutectic phase, making liquid phases to expand along grain boundaries, increasing the ability of liquid phases to permeate surrounding microstructures ${ }^{[23]}$, and thus wetting particles and accelerating the process of transformation from original dendrite to non-dendrite microstructures.

Continuing to increase the temperature to $595{ }^{\circ} \mathrm{C}$, the fraction of liquid phases apparently increases and solid particles are completely separated suspended unevenly in liquid phases. The shape factors and average particle sizes of all alloys rise slightly compared to those of alloys heat treated at $585{ }^{\circ} \mathrm{C}$ for $30 \mathrm{~min}$. According to Arrbenins' formula between the alloy diffusion coefficient $D$ and temperature $T^{[24]}$.

$$
D=D_{0} \exp \left(\frac{-Q}{R T}\right)
$$

where $Q\left(\mathrm{~J}^{\mathrm{m}} \mathrm{mol}^{-1}\right)$ is the diffusion activation energy, $D_{0}\left(\mathrm{~m}^{2} \cdot \mathrm{s}^{-1}\right)$ is the diffusion constant, $R\left(8.314 \mathrm{~J} \cdot \mathrm{mol}^{-1} \cdot \mathrm{K}^{-1}\right)$ is the gas constant and $T(\mathrm{~K})$ is the absolute temperature. So, raising temperatures can enhance the ability of atomic diffusivity, making the eutectic phase dissolved sufficiently and accelerating to separate the process of the solid phase. In addition, when the temperature of isothermal heat-treating is excessively high, such as $595{ }^{\circ} \mathrm{C}$, although it will lead to the difficulty in the mergence and growth of solid particles, the
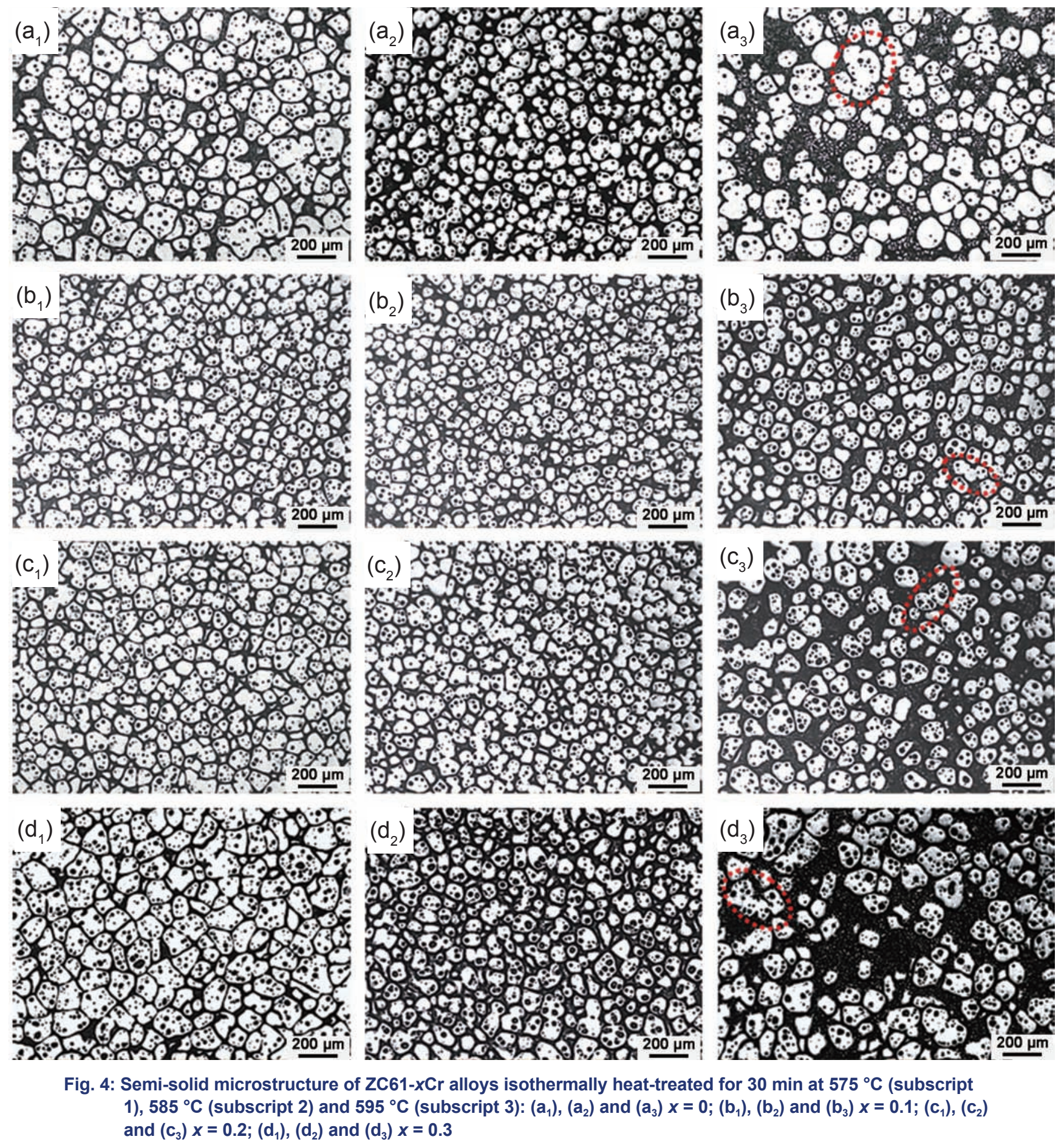

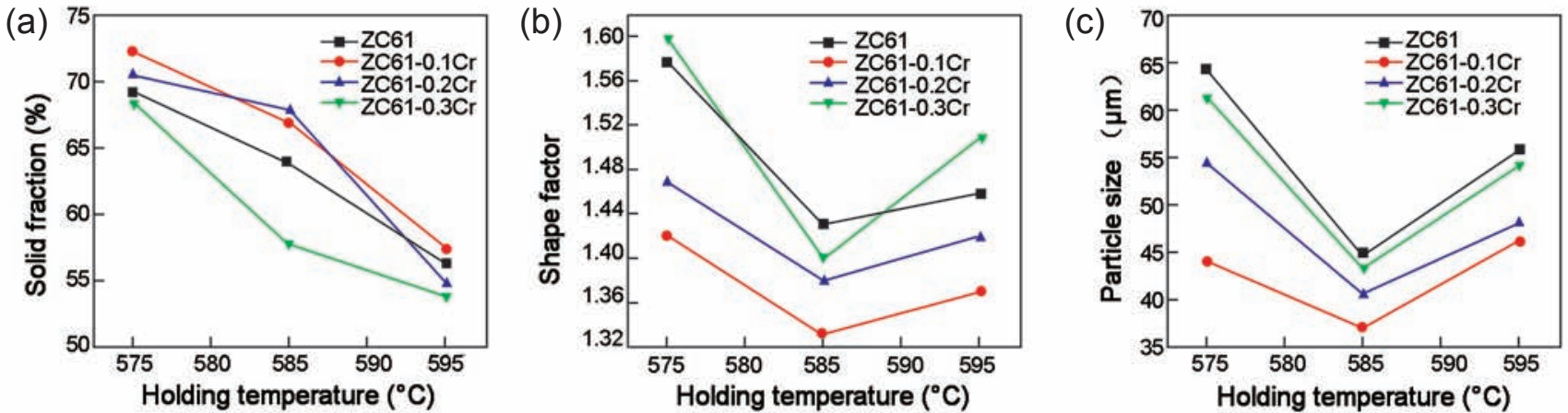

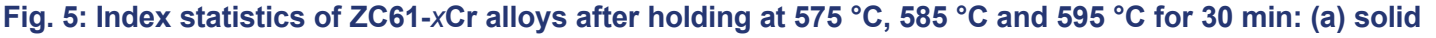

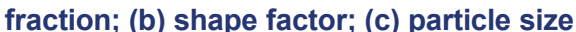

higher surface energy still exists in the fine particles of the melt, and the primary $\alpha-\mathrm{Mg}$ particles between liquid phases can still be remelted and adhere together to grow into coarse and irregular particles [marked by red circles in Fig. 4( $\left.a_{3}\right),\left(b_{3}\right)$, $\left(c_{3}\right)$ and $\left(d_{3}\right)$ ]. Meanwhile, the shape factors of solid particles of all alloys are improved slightly, as shown in Fig. 5(b). At $595{ }^{\circ} \mathrm{C}$ holding for $30 \mathrm{~min}$, the size of solid particles increased due to the coarsening mechanism, as observed in Fig. 5(c).

As observed from the longitudinal direction of Fig. 4, with the increase of $\mathrm{Cr}$ contents, the average solid particle sizes of experimental alloys under the same temperature increase (shown in Fig. 5c), but the sizes are still lower than that of the ZC61 alloy, indicating the addition of $\mathrm{Cr}$ can reduce the average size of primary $\alpha-\mathrm{Mg}$ particles. This is because grains are refined and most of them are nearly fine equiaxed and roselike when $\mathrm{Cr}$ was added to ZC61 alloy (Fig. 1), especially when $\mathrm{Cr}$ content was $0.1 \mathrm{wt} . \%$, this is consists with the research results of $\mathrm{Wu}$ et al. ${ }^{[25]}$. In additon, The solubility of $\mathrm{Cr}$ in the magnesium matrix is extremely low ${ }^{[16]}$ and it possibly enriches in liquid phases between solid phase particles during SSIHT, which refrains the diffusion of other atoms and slows down the process of Ostwald ripening. And according to the relation of interface energy, only when it is conformed to $\gamma_{\mathrm{ss}}<\gamma_{\mathrm{sl}}$, where $\gamma_{\mathrm{ss}}\left(\mathrm{J} \cdot \mathrm{m}^{-2}\right)$ is the interface energy of all solid phases, $\gamma_{\mathrm{sl}}\left(\mathrm{J} \cdot \mathrm{m}^{-2}\right)$ is the interface energy of all liquid phases, two solid particles can be welded together ${ }^{[26]}$. However, $\mathrm{Cr}$ element concentrated in liquid phases between solid particles causes the increase of $\gamma_{\mathrm{ss}}$, making it hard to meet the above formula, thus it can increase the difficulty of particles merging and prevent the further coarsening of solid particles effectively (especially at $595^{\circ} \mathrm{C}$ ). So the average size of solid phases decreases, and the addition of $\mathrm{Cr}$ can be beneficial to the mechanical properties of the alloy after semi-solid forming.

In Fig. 5(a), the solid fraction of all alloys decreases with the increase of temperature. Compared with ZC61 alloy, the solid fractions of semi-solid alloys vary slightly when the content of $\mathrm{Cr}$ is $0.1 \mathrm{wt} . \%$ and $0.2 \mathrm{wt} . \%$, nevertheless, there is a great change when the content of $\mathrm{Cr}$ is $0.3 \mathrm{wt} . \%$ (Fig. 5a). This is because the contribution of $\mathrm{Cr}$ to the proportion of as-cast eutectic phases does not change greatly when the amount of $\mathrm{Cr}$ is $0.1 \mathrm{wt} . \%$ and $0.2 \mathrm{wt} . \%$, but when the content of $\mathrm{Cr}$ is $0.3 \mathrm{wt} . \%$, the number of eutectic phases obviously increases (as shown in Fig. 1). Considering the low solubility of $\mathrm{Cr}$ in the magnesium, it can be concluded that $\mathrm{Cr}$ is not completely dissolved into the magnesium matrix and it has concentrated in grain boundaries when the content of $\mathrm{Cr}$ is more than $0.2 \mathrm{wt} . \%$.

For shape factors of semi-solid alloys, a clear downward trend appears when the addition of $\mathrm{Cr}$ is $0.1 \mathrm{wt} . \%$ and $0.2 \mathrm{wt} . \%$ (Fig. 5b), and their shape factors are 1.33 and 1.38 respectively when treated at $585{ }^{\circ} \mathrm{C}$ for $30 \mathrm{~min}$. This is mainly due to the refinement of as-cast microstructure and formation of nearly equiaxed or rose-like grains caused by addition of $\mathrm{Cr}$.

\subsubsection{Effects of different holding times on semi-solid microstructural evolution of ZC61-0.1Cr alloy}

According to the above analyses, the ZC61-0.1Cr alloy has ideal semi-solid microstructure at $585{ }^{\circ} \mathrm{C}$. It was decided to investigate the evolution of non-dendritic microstructures at $585{ }^{\circ} \mathrm{C}$ holding for different times, as shown in Fig. 6. The corresponding curves of solid fraction, shape factor and grain size of the alloy are shown in Fig. 7. As shown in Fig. 6(a), after holding for $15 \mathrm{~min}$, the dendritic microstructure in as-cast alloy has transformed into nearly spherical or a few irregular $\alpha-\mathrm{Mg}$ particles, the liquid phase between solid particles has also completely connected. There are also many "liquid pools" of different sizes inside solid particles. The solid fraction and shape factor are $73.5 \%$ and 1.66 , respectively. When the time increases to $30 \mathrm{~min}$, as shown in Fig. 6(b), fine particles with ideal spheroidization effect are evenly distributed in the liquid phase. The size of $\alpha-\mathrm{Mg}$ particles is rapidly reduced to $37.5 \mu \mathrm{m}$ from $57.5 \mu \mathrm{m}$, the average shape factor is 1.33 , and the number of irregular massive particles relatively decreases and become nearly spherical. During holding for $45 \mathrm{~min}$ and 60 min, as shown in Fig. 6(c) and (d), the solid fraction of $\alpha-\mathrm{Mg}$ particles continuously decreases from $57.7 \%$ to $52.9 \%$, the number and shape factor of solid particles apparently decreases and increases, respectively. This is mainly due to the coarsening process of $\alpha-\mathrm{Mg}$ particles, including the mechanism of combining growth and Ostwald ripening. The Ostwald ripening mechanism is characterized by the melting 

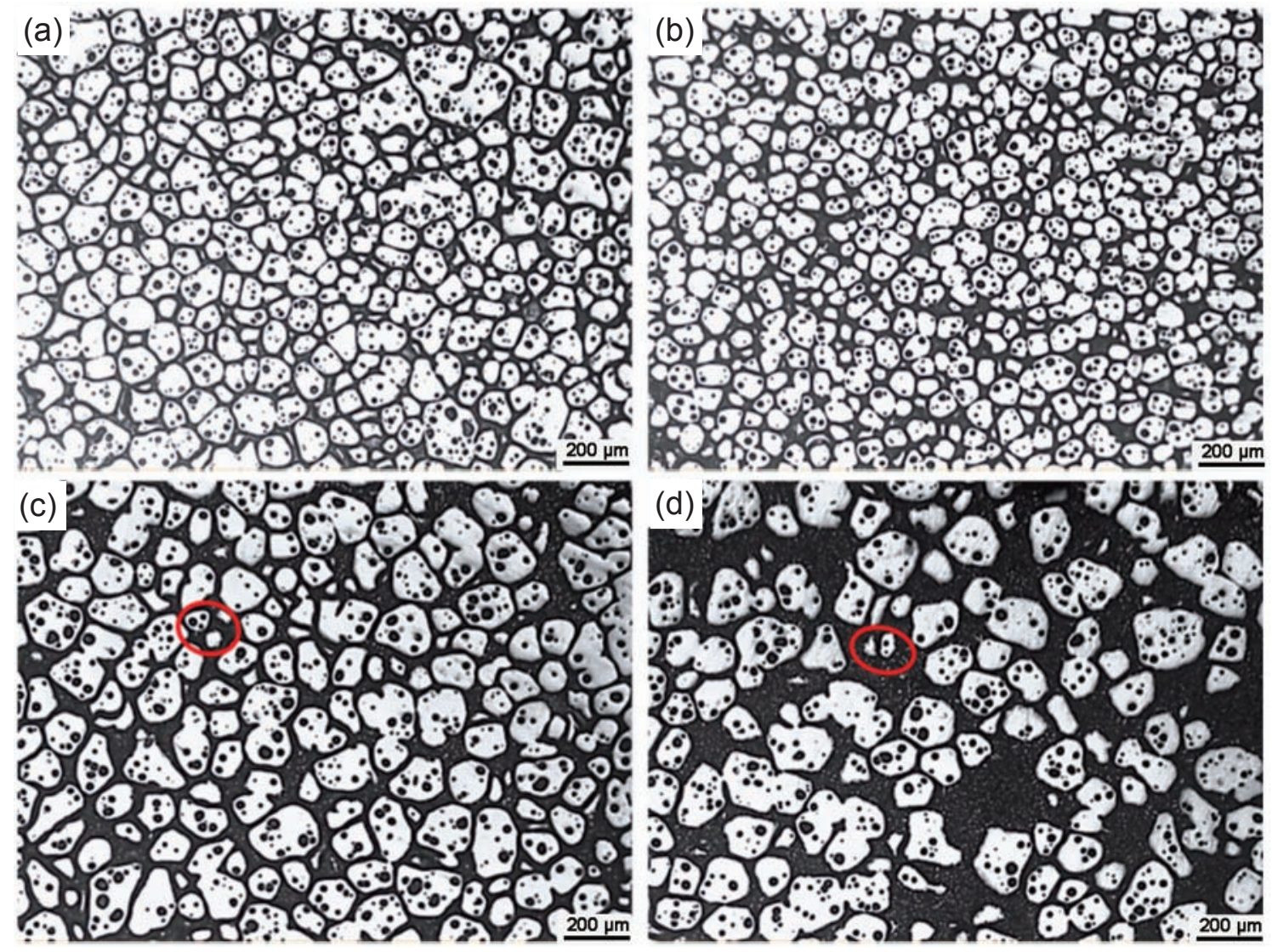

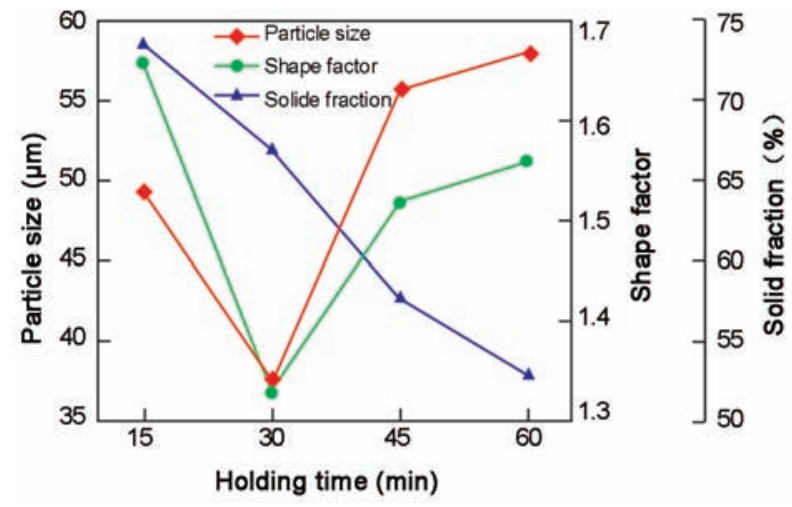

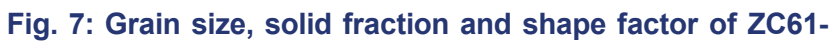

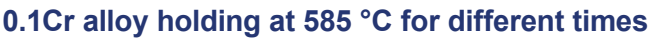

disappearance of fine-sized particles (marked by red circles) and the growth of large-sized particles, conforming to the following formula ${ }^{[27]}$ :

$$
d_{\mathrm{t}}^{3}-d_{0}^{3}=k_{0} t
$$

where $d_{\mathrm{t}}(\mu \mathrm{m})$ is the average size of the solid phase particles at time $t, d_{0}(\mu \mathrm{m})$ is the average size of the initial solid phase particles, $k_{0}\left(\mu \mathrm{m}^{3} \cdot \mathrm{s}^{-1}\right)$ is the coarsening rate constant, and $t(\mathrm{~s})$ is the holding time. Therefore, large-sized particles coarsening is obvious. For combining growth mechanism, it is characterized by the formation of two or more particles in mutual contact almost instantaneously. From the increment of shape factor shown in Fig. 7, it can be inferred that the mechanism of combining growth plays a main role during the holding time.

\subsubsection{Semi-solid microstructural characterization}

In the process of SSIHT, the essence of non-dendritic microstructural evolution is a phase transformation process mainly owing to solute atoms diffusion and energy fluctuation ${ }^{[28]}$. In order to analyze the characterization of non-dendritic microstructure and solute atoms diffusion of $\mathrm{Mg}-\mathrm{Zn}-\mathrm{Cu}-\mathrm{Cr}$ alloy during SSIHT, the non-dendritic microstructure of ZC61-0.1Cr alloy holding at $585^{\circ} \mathrm{C}$ for $30 \mathrm{~min}$ is taken as an example. The corresponding SEM graphs of non-dendritic microstructures and distributions of $\mathrm{Mg}, \mathrm{Zn}, \mathrm{Cu}$ and $\mathrm{Cr}$ elements in the alloy are shown in Fig. 8. It can be seen from Fig. 8(a) that the solid phases in shape are close to spherical, ellipsoid and irregular, and the microstructure is mainly constituted of $\alpha_{1}-\mathrm{Mg}$ and $\alpha_{2}$ $\mathrm{Mg}$ phases formed by the primary and secondary solidification, respectively. Liquid phases solidified after water quenching are composed of cellular eutectic phases, similarly straight or curve phases and "liquid pools" isolated in interior particles. In addition, compared with the eutectic microstructure of the as-cast alloy, the morphology of eutectic microstructure in the semi-solid alloy has been greatly changed from primitive thin sheet-like and fishbone to cellular and linear. The edges of some eutectic microstructures are the shape of serrations, 


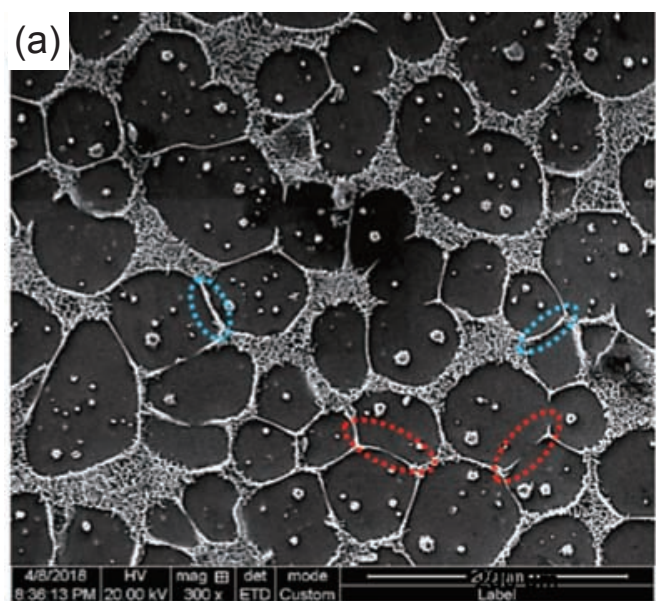

Mg ka1-2

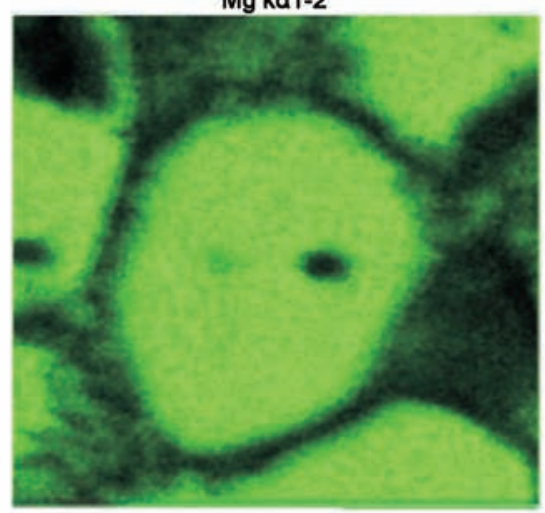

$25 \mu \mathrm{m}$

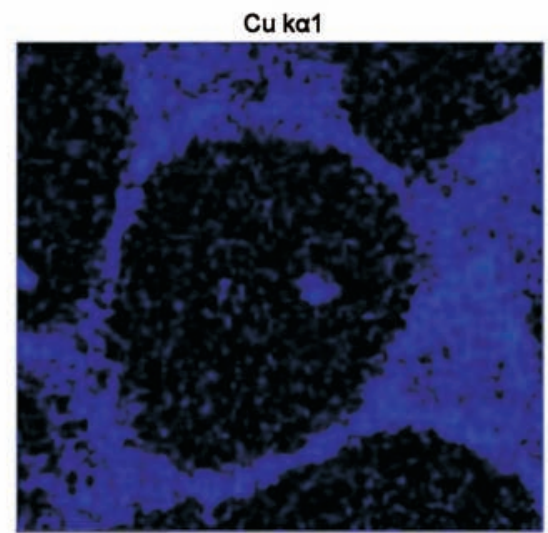

$25 \mu \mathrm{m}$

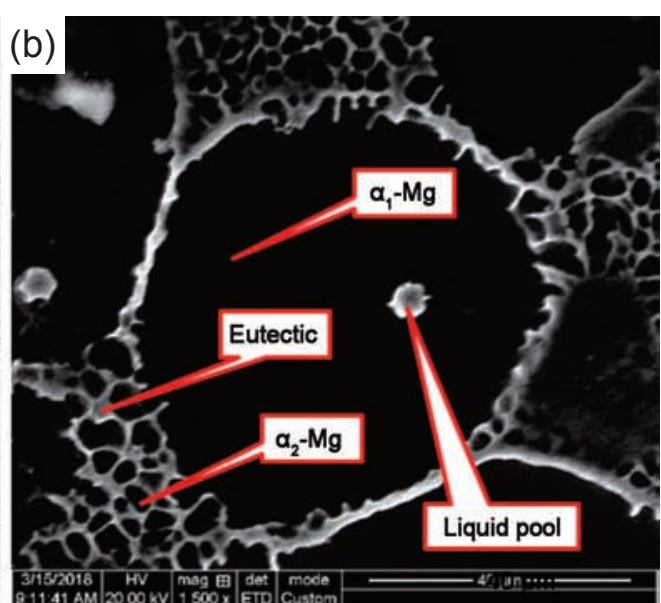

Zn ka1

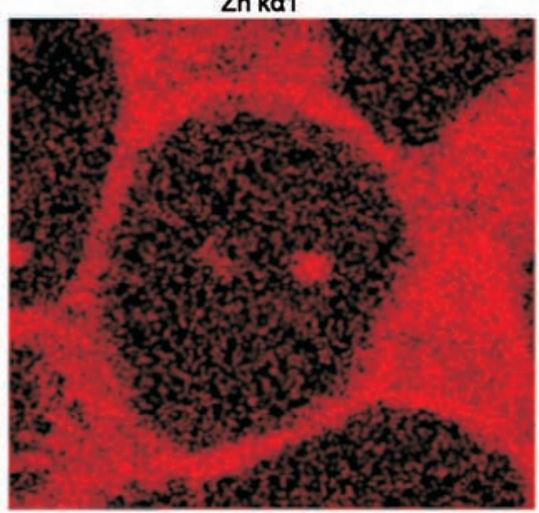

$25 \mu \mathrm{m}$

Cr ka1

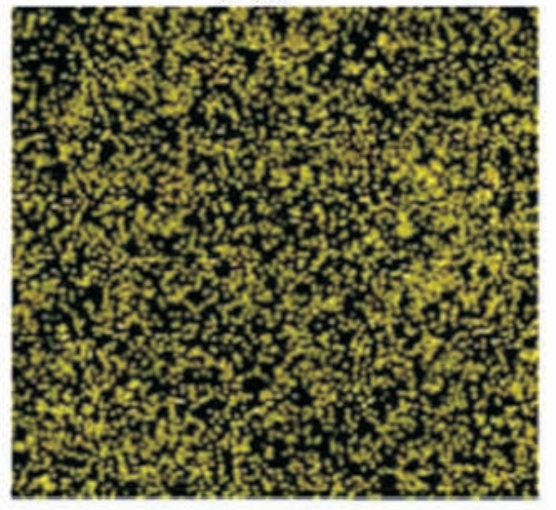

$25 \mu \mathrm{m}$

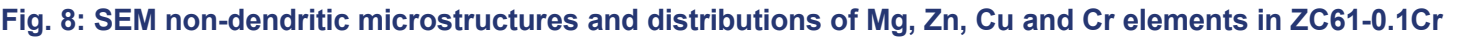

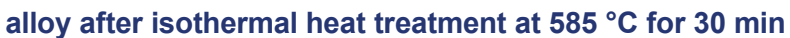

which is mainly due to the diffusion of liquid solute. It can be indicated that the diffusion of solute is not complete or the mechanism of coarsening has come into effect. Cao et al. ${ }^{\text {[29] }}$ reported that non-dendritic microstructural evolution was mainly atoms diffusion in the interior of the alloy, because the temperature of partial remelting is between solidus and liquidus. It can be seen from area scan of Fig. 8(b) that $\mathrm{Mg}$ atoms are mainly enriched in solid particles and $\mathrm{Zn}$ and $\mathrm{Cu}$ atoms enriched in liquid phases, but $\mathrm{Cr}$ atoms are relatively evenly distributed in all areas without segregation. This is because the atomic radius of $\mathrm{Cr}$ is $0.125 \mathrm{~nm}$, which is lower than atomic radiuses of $\mathrm{Mg}, \mathrm{Zn}$ and $\mathrm{Cu}(0.160,0.139$ and $0.128 \mathrm{~nm}$, respectively). So, $\mathrm{Cr}$ atoms are easier to diffuse than others, thus are distributed evenly. $\mathrm{Cr}$ can be dissolved in the magnesium lattice in the presence of $\mathrm{Zn}$ and $\mathrm{Cu}$, consisting to the result of Ref. [16]. This may cause the lattice diffusion of the alloy to be hindered, thereby reducing the rate of phase transformations and slowing down the process of non-dendritic microstructural evolution of the alloy before reaching the maximum solubility of $\mathrm{Cr}$ in magnesium (adding $0.1 \mathrm{wt} . \%$ and $0.2 \mathrm{wt} . \%$ ).

As shown in the red circles of Fig. 8(a), similarly straight 
liquid phases show a necking phenomenon during the evolution of non-dendritic microstructure, explaining by the following formula ${ }^{[30]}$ :

$$
\Delta T_{\mathrm{r}}=-\frac{2 \sigma T_{\mathrm{m}} V_{\mathrm{s}} k}{\Delta H_{\mathrm{m}}}
$$

where $\Delta T_{\mathrm{r}}(\mathrm{K})$ is the equilibrium melting point of solid and liquid phases, $\sigma\left(\mathrm{N} \cdot \mathrm{m}^{-1}\right)$ is the solid-liquid interfacial tension, $T_{\mathrm{m}}(\mathrm{K})$ is the melting point of the solid-liquid interface, $V_{\mathrm{s}}$ $\left(\mathrm{L} \cdot \mathrm{mol}^{-1}\right)$ is the molar volume of solid phase, $\Delta H_{\mathrm{m}}\left(\mathrm{J} \cdot \mathrm{mol}^{-1}\right)$ is the solid-liquid transformation of molar enthalpy change and $k\left(\mathrm{~m}^{-1}\right)$ is the curvature of the solid-liquid interface. According to the formula, the smaller the radius of curvature of eutectic phases, the lower the melting point, the easier to melt during the process of remelting. Thus, when the treating temperature is low or the holding time is short, solute components in the alloy are in the state of homogeneous diffusion. These solute components diffuse into the interior of dendritic arms, causing secondary phases to dissolve continuously and making dendritic arms merge. When the treating temperature or the holding time increases, under the circumstance that the melting point is lower, dendritic arms are the first to melt and detach, forming particles with different sizes and shapes. According to SEM area scan, it can be concluded that non-equilibrium eutectic phases containing high $\mathrm{Zn}$ and $\mathrm{Cu}$ atoms are mainly enriched at the both ends of the necking regions, and the curvature radius of these parts is small. The composition of $\mathrm{Zn}$ and $\mathrm{Cu}$ in liquid phases fluctuates greatly during the heat treatment process, the eutectic phases are preferentially melted into liquid phase and gradually infiltrated into the root of dendritic arms under the pure diffusion condition. So, necking occurs under the action of interfacial tension during separation and spheroidization of particles.

\section{Conclusions}

(1) The as-cast microstructure of ZC61- $x \mathrm{Cr}(x=0,0.1$, $0.2,0.3)$ magnesium alloys is mainly composed of $\alpha-\mathrm{Mg}$, $\mathrm{CuMgZn}$ and $\mathrm{MgZn}_{2}$ phases; in semi-solid microstructures, solid particles are composed of $\alpha_{1}-\mathrm{Mg}$ and $\alpha_{2}-\mathrm{Mg}$ phases, and liquid phases solidified after water quenching are composed of cellular eutectic phases, nearly straight or curve phases, and "liquid pools" isolated in interior particles.

(2) Grains in the as-cast microstructure of ZC61 alloys can be relatively refined when the content of $\mathrm{Cr}$ is $0.1 \mathrm{wt} . \%$, and as $\mathrm{Cr}$ contents increase to $0.3 \mathrm{wt} . \%$, the grain size of experimental alloys increases and eutectic phases coarsen. When ZC61- $x \mathrm{Cr}$ alloys are isothermally heat-treated at different temperatures for $30 \mathrm{~min}$, solid particles and shape factors of experimental alloys decrease first, and then increase as the temperature increase from 575 to 585 and $595{ }^{\circ} \mathrm{C}$. Meanwhile, solid fractions are continuously decreased with the increasing temperature; and when ZC61-0.1 alloy was treated at $585{ }^{\circ} \mathrm{C}$, the best solid particle size and shape factor of $37.5 \mu \mathrm{m}$ and 1.33 , can be obtained.

(3) Compared with the alloy without added Cr element, the addition of $\mathrm{Cr}$ can reduce the average size of primary $\alpha-\mathrm{Mg}$ particles under the same temperature and time, and it is also apparently indicated that the addition of $\mathrm{Cr}$ can refrain the coarsening process of primary $\alpha-\mathrm{Mg}$ particles. But, there is still a coarsening phenomenon in the ZC61-0.1Cr alloy treated at $585^{\circ} \mathrm{C}$, especially after holding for $45 \mathrm{~min}$, and the coarsening is affected by both combining growth and Ostwald ripening mechanism.

\section{References}

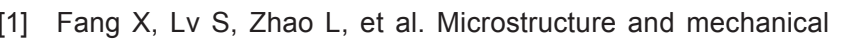

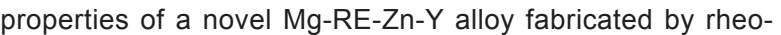

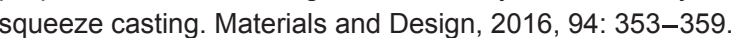

प

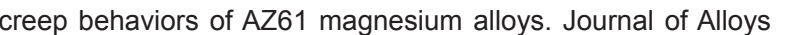

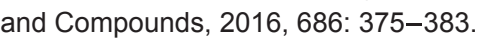

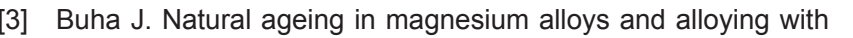
Ti. Journal of Materials Science, 2008, 43(4): $1220 \square \square$

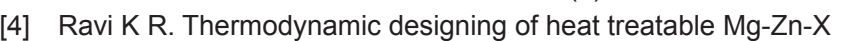
$(\mathrm{X}=\mathrm{Sn}, \mathrm{Y})$ alloy suitable for semi-solid processing. Transactions of the Indian Institute of Metals, 2016(6): $32 \square \square \square$

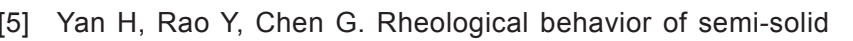

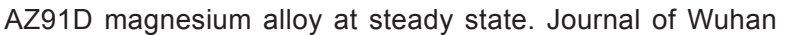
University of Technology (Materials Science Edition), 2015, 30(1): $162 \square \square \square \square$

(10)

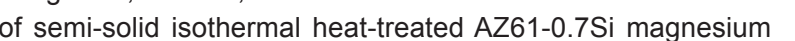
alloy. The Chinese Journal of Nonferrous Metals, 2009, 19(1): $\square \square \square \square$

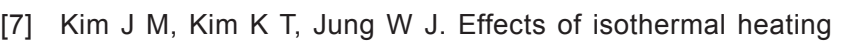

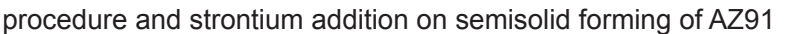
magnesium alloys. Metal Science Journal, 2013, 18(6): $698 \square$ प्वापा

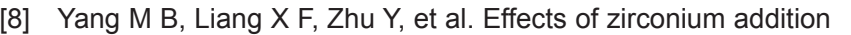

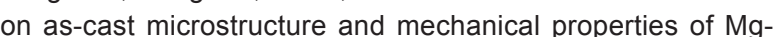
3Sn-2Ca magnesium alloy. Materials and Design, 2011, 32(4):

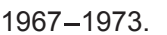

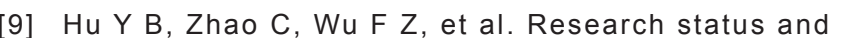

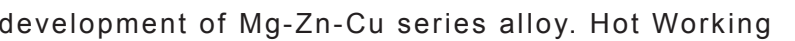
Technology, 2012, 41(2): 16 19.(In Chinese)

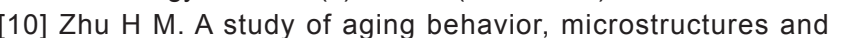
mechanical properties of cast $\mathrm{Mg}-6 \mathrm{Zn}-\mathrm{xCu}-0.6 \mathrm{Zr}(\mathrm{x}=0-2.0)$

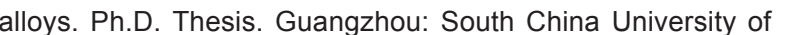

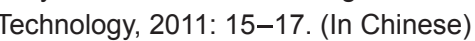

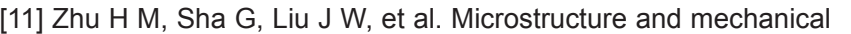
properties of $\mathrm{Mg}-6 \mathrm{Zn}-\mathrm{xCu}-0.6 \mathrm{Zr}$ (wt.\%) alloys. Journal of Alloys and Compounds, 2011, 509(8): 3526

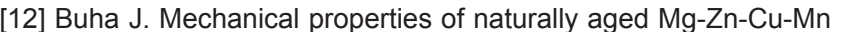

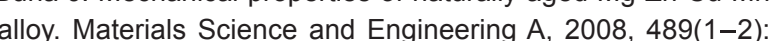

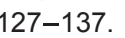

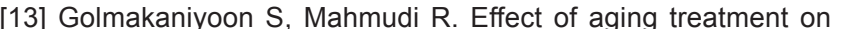

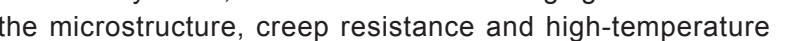

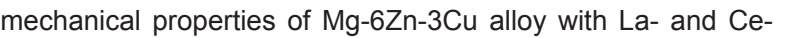
प

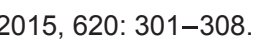

(⿴囗十) [ and Nonferrous Alloys, 2010, 30(3): $279 \sqsubset 282$. (In Chinese)

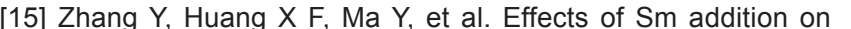

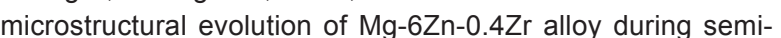
solid isothermal heat treatment. China Foundry, 2017, 14(2): $\square\left[\begin{array}{ll}0 \\ \square\end{array}\right.$ 


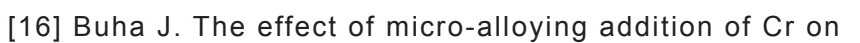

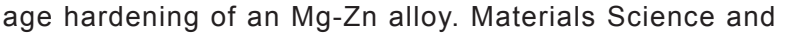

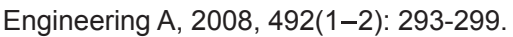

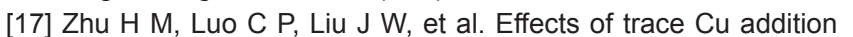

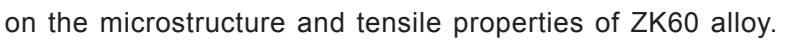

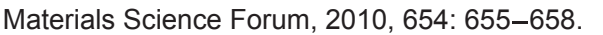

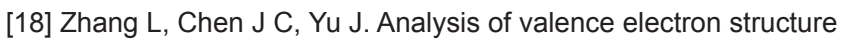

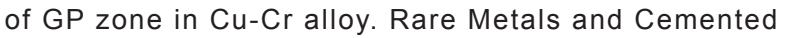
Carbides, 2006, 34(4): 28 31. (In Chinese)

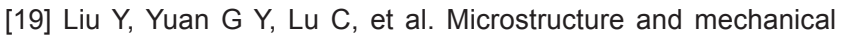

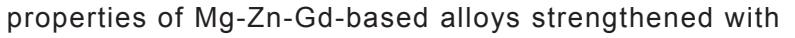

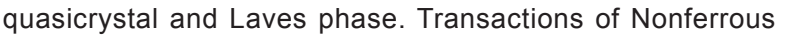
Metals Society of China, 2007, 17(s1): $353 \square \square \square$

[20] Buha $\mathrm{J}$ and Ohkubo T. Natural aging in $\mathrm{Mg}-\mathrm{Zn}(-\mathrm{Cu})$ Alloys. Metallurgical and Materials Transactions A, 2008, 39(9): $2259 \square$ $\square\left[\begin{array}{lll}\square \\ 0\end{array}\right.$

[21] Nayeb-Hashemi A A, Clark J B (Eds). Phase diagrams of

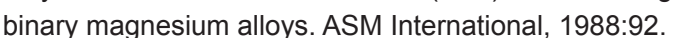

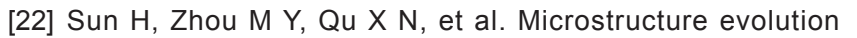

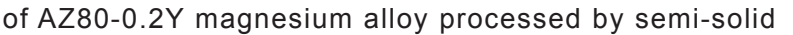

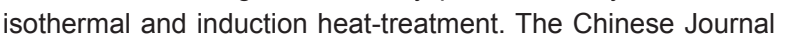
of Nonferrous Metals, 2017,27(10): 1988 1995. . (In Chinese)

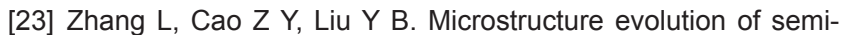

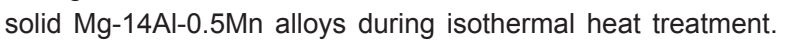

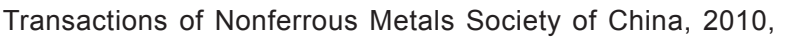
20(7): $1244 \square \square \square \square$
प

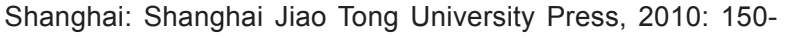
151. (In Chinese)

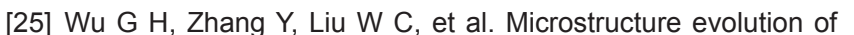

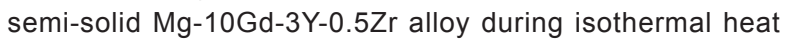
treatment. Journal of Magnesium and Alloys, 2013, 1(1): $39 \square$ $\square \square \square$

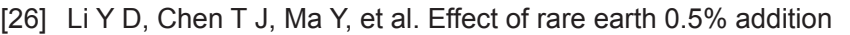

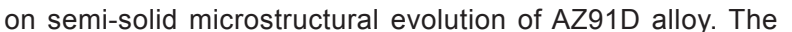
Chinese Journal of Nonferrous Metals, 2007, 17(2): $320 \square \square \square$ (In Chinese)

(स)

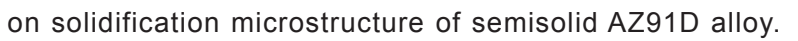

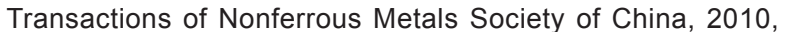
20(s3): $868 \square \square \square$

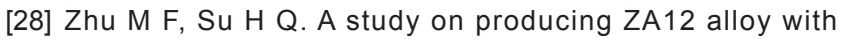
$\mathrm{F}$
$\mathrm{F}$ Foundry, 1996(4): 1 5. (In Chinese)

प

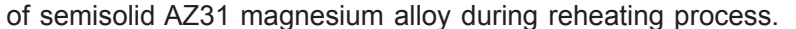
The Chinese Journal of Nonferrous Metals, 2012, 22(1): $7 \square \square \square$ (In Chinese)

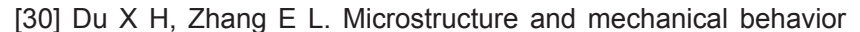

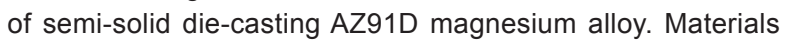
Letters, 2007, 61(11-12): $2333 \square \square \square \square$ 